SELECTION FOR YIELD IN SMALL PLOTS OF SPRING WHEAT

Th. KRAMER, J. W. VAN OOIJEN and C. J.T. SPITTERS

Offprint from Euphytica 31 (1982) 549-564 



\title{
SELECTION FOR YIELD IN SMALL PLOTS OF SPRING WHEAT
}

\author{
Th. KRAMER 1 , J.W. VAN OOIJEN ${ }^{1}$ and C. J. T. SPITTERS ${ }^{2}$ \\ ${ }^{1}$ Institute of Plant Breeding, Agricultural University, Wageningen, the Netherlands \\ ${ }^{2}$ Department of Theoretical Production Ecology, Agricultural University, Wageningen, the Netherlands
}

Received 24 February 1982

\begin{abstract}
INDEX WORDS
Triticum aestivum, wheat, grain yield, selection.

SUMMARY

Four selection experiments were sown: single-row plots with single row-spacing ( $\simeq 20 \mathrm{~cm})$, single-row plots with double row spacing $(\simeq 40 \mathrm{~cm})$, three-row plots and six-row plots both with single row-spacing $(\simeq 20 \mathrm{~cm})$. Selection entries were mimiced by 16 different varieties or advanced breeding lines, which were also sown in a yield trial. Each experiment was laid out as a 4-times replicated randomized block design. Row length was $2 \mathrm{~m}$. Alley borders and border-rows of multiple-row plots were harvested separately to evaluate the effects of different harvesting procedures on the selection efficiency. Removal of alley borders was found to be disadvantageous, since the gain in precision was more than offset by the loss in sampled area. Wide spacing of single-row plots improved the selection efficiency in comparison with normal spaced single-row plots. In multiple-row plots the selection efficiency was not improved by harvesting only the central rows.

For gross plot yield ( $=$ yield of net plot + yield of alley borders) the differences in selection efficiency between the various selection plot-types were explained on the basis of the genetic variance, the environmental variance and the coefficient of genetic correlation with 'farm' yield as determined in the yield trial.
\end{abstract}

\section{INTRODUCTION}

Use of small plots for yield evaluation in cereal breeding has attracted attention for two main reasons. First, from a theoretical point of view, selection should start in the $F_{3}$ generation (SHEBESKI, 1967). The limited amount of seed harvested on single $F_{2}$ plants dictates $F_{3}$ yield testing on plots small in size. An additional advantage is that testing in small plots facilitates evaluation in an earlier generation than is customary. Second, in later generations, when the amount of seed is not a restriction one could prefer small plots in order to evaluate a larger number of lines than is possible with large plots. This has the advantage that the selection intensity can be increased by testing for yield a wider spectrum of lines. A's a result of the selection, response is expected to improve.

On the contrary there are also a number of objections against yield-testing in small plots. These objections are related with the problems of cost and identification of superior lines. With early-generation yield testing there are the additional problems of segregation and of heterozygosity within the lines (SPITTERs, 1979; p. 5-6). 
Results of yield selection based on the performance of small $\mathrm{F}_{3}$ plots have been inconsistent (Alessandroni \& SCAlfati, 1973; Briggs \& Shebeski, 1971; DePauw \& SHEBESKI, 1973; SEITZER \& EVANS, 1978), but generally the response in later generations after selection for yield in earlier generations was disappointing.

To what extent this is indebted to genetic segregation, identification problems (random errors inherent to small samples) or to genotype $\times$ year interaction cannot be established, since the effects of these phenomena are confounded.

Little systematic information is available on the relative contributions of the three phenomena to the ineffectiveness of yield selection in $\mathrm{F}_{3}$ plots.

Recently, WHAN et al. $(1981,1982)$ showed that associations between consecutive generations were closer in later than in early generations, pointing to the fact that the degree of homozygosity influences the correlation between generations.

Genotype $\times$ year interaction, expressed in terms of variance components or measured by a correlation coefficient between the performances of lines grown in different years, may also hamper selection success considerably.

WHAN et al. (1981) showed that the correlation between $F_{3}$ and $F_{6}$ lines was acceptable when lines of both generations were grown in the same year. This indicates that selection among $F_{3}$ lines will give satisfactory results in the absence of genotype $\times$ year interaction. In contrast, the correlation between lines of different generations tested in different years was low and insignificant. As a result the response to selection when measured in different years was little better than random selection (WHAN et al., 1982).

Random effects are also of importance. Especially in small plots, where lines are selected rather as a result of favourable incidental environmental conditions than as a result of the superiority of the lines.

A low correlation between yield of $F_{3}$ lines and their progeny in later generations is thus not unexpected. However, opposed to this drawback there is the fact that early generation yield testing offers the advantage to screen over a prolonged number of years for yield stability.

Since genetic segregation, genotype $\times$ year interaction and random effects are disturbing elements inherent to the breeding process, the precision of yield evaluation in small plots becomes of eminent importance.

Removal of artefacts like competition between genotypes growing in neighbouring plots or alley effects and reduction of random effects, which bias the genotypic differences in a given year, improve the selection technique.

In this paper attention is focussed on the precision of yield estimates obtained from various commonly used small-size selection plots. Several harvesting procedures are compared. In addition, a method is applied to adjust for differences in plant establishment and interplot competition. Effects of genetic segregation and genotype $\times$ year interaction were excluded by using varieties and evaluating within one season. A replicated yield trial with the same set of varieties grown in large field plots to establish their performance under 'farm' conditions formed the reference for the determination of the effectiveness of selection in the studied selection plot variant. This approach is similar to the one used by Spitters for the experimental evaluation of competition effects in barley (SPITTERS, 1979). 
General. All selection plots were planted with a 'Seedmatic' plot seeder produced by the firm Walter and Wintersteiger. For planting the yield trial a six-row Øyord machine was used. Seedmatic plots were $2 \mathrm{~m}$ long, the row distance being in general $20.8 \mathrm{~cm}$. Øyord plots consisted of rows of $6 \mathrm{~m}$ length with a row distance of $25 \mathrm{~cm}$. For each plot-type interplot spacing was equal to inter-row spacing. Sowing density in all plots was 250 seeds $\mathrm{m}^{-2}$, except in selection plots with a double row-spacing, where only half this sowing density occurred. Experiments were sown in the first week of April 1980; the selection plots a few days after the yield trial. A total of 16 different spring wheat varieties or advanced breeding lines were chosen as plant material for the experiments.

Selection plots and yield experiment. Basically four different types of selection plots were chosen, i.e. single-row plots with single row-spacing $(\simeq 20 \mathrm{~cm})$, single-row plots with double row-spacing $(\simeq 40 \mathrm{~cm})$, three-row plots and six-row plots both with single row-spacing $(\simeq 20 \mathrm{~cm})$. Each of these types of selection plots was accomodated within a separate randomized block experiment replicated in fourfold. Experiments were located next to each other in the field for practical purposes, although randomization of plot-types is desirable from a statistical point of view.

Furthermore, several harvesting methods were applied. These methods are called variants. Firstly, in the three-row and six-row selection plots the two outer-rows were harvested separately from the inner-row(s). Selection for grain yield was carried out both on the basis of central plots as well as total plots. Yields of central plots are not affected by intergenotypic competition, since effects of competition are restricted to neighbour rows (FISCHER, 1979; SPITTERS, 1979: p. 42-40; AUSTIN \& BlaCKWELL, 1980).

Two other variants were net plots and gross plots For this difference the outer 25 $\mathrm{cm}$ row length of each plot bordering the alleys was harvested separately. Net plots were thus harvested over a row length of $1.5 \mathrm{~m}$, gross plots over the total row length of $2 \mathrm{~m}$.

After emergence of the seedlings considerable irregularities in stand were observed. These were probably the result of dry weather shortly after sowing, which killed germinating seeds positioned too close to the soil surface. For each row the total length of gaps with a minimum length of $10 \mathrm{~cm}$ each was estimated. A standfactor for each plot-type and each variant was calculated by summing the total length of gaps. The standfactor was used in one of the procedures for adjusting the yield.

In the selection plots grain yield and biomass yield were determined. Both variables were expressed as dry matter in $\mathrm{g} \mathrm{plot}^{-1}$. In the yield trial an area of one $\mathrm{m}^{2}$ was handharvested for determination of biomass yield $\left(\mathrm{g} \mathrm{m}^{-2}\right)$ by cutting the plants directly above soil level. The remaining part of the plot was combine-harvested. Plot grain yield included the yield from grain of the biomass sample. The experimental design of the yield trial was similar to that of the selection plot experiments.

Statistical analysis. An analysis of variance was obtained for each of the variants of each of the selection plot-types and the yield trial. From this analysis estimates of the environmental variance (var e) and the genetic variance (var g) were obtained, 
in addition to estimates of the coefficient of variation $(\mathrm{CV})$ and the heritability $\left(\mathrm{h}^{2}\right)$. Furthermore, phenotypic and genetic correlation coefficients were estimated between grain yield in each one of the selection plot variants and grain yield in the yield trial. For formulas and derivations see the appendix.

The effectiveness of the selection plot variants in yield selection for field performance can be compared on the basis of a single parameter, the phenotypic correlation coefficient $\left(\rho_{\mathrm{p}}\right)$. The derivation is given in the appendix.

Differences in plant number per row will influence the performance per row (SPITTERS, 1979; p. 230). Gaps in a row will influence the plant number per row and thereby the performance of this row and its direct neighbour rows. VAN DE VEN (1981) found that single gaps up to a length of $40 \mathrm{~cm}$ per row were completely compensated for both within the particular row and its direct neighbours. Roughly $2 / 3$ of the yield loss was distributed equally to the two neighbour rows and $1 / 3$ to the particular row itself. In an attempt to adjust the yield per plot for differences in plant number an effective stand for each selection plot variant was calculated. The effective stand $a_{i}$ of plot $i$ is defined as the potential row length of all rows in that plot minus the total length of the gaps. Subsequently the relative stand $\mathrm{a}_{i}^{\prime}$ of a plot in relation to the border rows of both neighbour plots was calculated as

$a_{i}^{\prime}=\frac{a_{i}}{a_{i}+1 / 2\left(a_{i-1}+a_{i+1}\right)}$

where $a_{i}^{\prime}=$ relative stand of plot $i, a_{i}=$ effective stand of plot $i, a_{i-1}=$ effective stand of border row $i-1, a_{i+1}=$ effective stand of border row $i+1$. The factor $\frac{1}{2}$ in the denominator is necessary since the interplot space is equally shared by two contiguous rows. $a_{i}^{\prime}$ was used as covariate in an analysis of covariance to adjust the plot yields.

Apart from expressing the available space in terms of occupied row length it was also expressed in terms of final biomass yield $\left(\mathrm{g} \mathrm{plot}^{-1}\right)$. For each plot the relative biomass

$b_{i}^{\prime}=\frac{b_{i}}{b_{i}+1 / 2\left(b_{i-1}+b_{i+1}\right)}$

was calculated and used as covariable. The purpose of this was an attempt to adjust for competitional differences between plots. The assumption underlying this adjustment is that biomass differences are the result of infringement of different genotypes on each others space.

When biomass differences between plots are not the result of differences in competitive ability, but of the genetical make-up of lines this correction method fails. However, there are indications that differences in biomass yield of genetical origin are relatively unimportant (Syme, 1970; Aguilar \& Fischer, 1975; Donald \& HAMBlin, 1976; JAIN \& KUHLSHRESTHA, 1976; KrAMER, 1979).

To facilitate the comparison between the selection plot variants the results are visually presented in histograms. The quantities $\mathrm{CV}, \mathrm{h}^{2}$ and $\rho_{\mathrm{p}}$ in these figures are based on mean values for yield over $\mathrm{n}=4$ replications, thus giving the perspectives of selection when the selection would be based on 4-times replicated entries. The quantities $\mathrm{CV}^{\prime}, \mathrm{h}^{2 \prime}$ and $\rho_{\mathrm{p}}^{\prime}$ refer to single, unreplicated plots. 
SELECTION FOR WHEAT YIELD

Table 1 . Grain yield in $\mathrm{g}$ plot ${ }^{1}$ and $\mathrm{g} \mathrm{m}^{2}$ and error variance in $\mathrm{g}^{2}$ plot ${ }^{2}$ of the experimental variants $(0 \%$ moisture).

\begin{tabular}{|c|c|c|c|c|c|c|}
\hline \multicolumn{3}{|c|}{ Selection plot-type } & \multicolumn{2}{|c|}{ Grain yield } & \multicolumn{2}{|c|}{ Error variance } \\
\hline & & & net plot & gross plot & net plot & gross plot \\
\hline \multirow{6}{*}{\multicolumn{3}{|c|}{$\begin{array}{l}\text { 1. single-row, single spacing }(\simeq 20 \mathrm{~cm}) \\
\text { 2. single-row, double spacing }(\simeq 40 \mathrm{~cm}) \\
\text { 3. three-row, central } \\
\text { 4. three-row, total } \\
\text { 5. six-row, central } \\
\text { 6. six-row, total }\end{array}$}} & $102(325)$ & $150(359)$ & 1073 & 1813 \\
\hline & & & $179(286)$ & $250(301)$ & 976 & 1469 \\
\hline & & & $110(350)$ & $163(391)$ & 596 & 1166 \\
\hline & & & $309(330)$ & $453(362)$ & 909 & 1743 \\
\hline & & & $400(320)$ & $585(351)$ & 1411 & 2086 \\
\hline & & & $602(321)$ & $879(352)$ & 3900 & 4981 \\
\hline \multicolumn{7}{|c|}{ Table 2. Statistics of crop characters in the yield trial. } \\
\hline Statistic & $\begin{array}{l}\text { Grain } \\
\text { yield } \\
\left(\mathrm{g} \mathrm{m}^{-2}\right)\end{array}$ & $\begin{array}{l}\text { Weight } \\
\text { of } 250 \text { kernels } \\
(0.1 \mathrm{~g})\end{array}$ & $\begin{array}{l}\text { Ear } \\
\text { number } \\
\left(\mathrm{m}^{-2}\right)\end{array}$ & $\begin{array}{l}\text { Kernel } \\
\text { number } \\
\left(\text { ear }^{-1}\right)\end{array}$ & $\begin{array}{l}\text { Biomass } \\
\left(\mathrm{g} \mathrm{m}^{-2}\right)\end{array}$ & $\begin{array}{l}\text { Harvest- } \\
\text { index } \\
(\times 100)\end{array}$ \\
\hline $\bar{x}$ & 324 & 90.22 & 265 & 33.6 & 723 & 45 \\
\hline var $\mathrm{g}$ & 645 & 66.38 & 607 & 12.9 & 2454 & 6.33 \\
\hline var $\underline{\mathrm{e}}$ & 360 & 28.12 & 424 & 9.1 & 2363 & 0.50 \\
\hline$\rho$ & 1 & 0.70 & 0.31 & -0.25 & 0.72 & 0.15 \\
\hline$h^{2}$ & 0.88 & 0.90 & 0.85 & 0.85 & 0.81 & 0.98 \\
\hline $\mathrm{CV}$ & 0.029 & 0,029 & 0.039 & 0.045 & 0.034 & 0.008 \\
\hline
\end{tabular}

\section{RESULTS}

General. The mean grain yields per plot and the corresponding error variances of the selection experiments are given in Table 1 . For clarity the grain yield in $\mathrm{g} \mathrm{m}^{-2}$ is placed between parentheses behind the plot yield.

The grain yield $\mathrm{m}^{-2}$ in the single-row plot selection experiment with double rowspacing was significantly lower than in each of the other selection plot variants. This indicated that no complete soil coverage was reached. The yield $\mathrm{m}^{-2}$ in the gross selection plot variants was higher than in the net variants (Table 1). This clearly demonstrated the yield increasing border effects with alleys. This effect was negligable in the yield trial (Table 2) because the yield $\mathrm{m}^{-2}$ was close to that in the net plots. The yield level was rather low for spring wheat in this part of the country. Some statistics of crop characters in the yield trial are represented in Table 2.

\section{Single row plots}

Single row-spacing $(\simeq 20 \mathrm{~cm})$. The coefficient of variation $(\mathrm{CV})$ for mean yield of gross plots is marginally lower than that of net plots (Fig. 1), although the differences after either one of the adjustment procedures were small. Correction of plot yield for differences in biomass resulted in a sharper decline of $\mathrm{CV}$ than correction for stand. The heritability $\left(\mathrm{h}^{2}\right)$ for grain yield was highest after biomass correction. However, variety effects for grain yield remained insignificant for either of the methods. The phenotypic correlation coefficient $\left(\rho_{\mathrm{p}}\right)$ had a weak tendency to be higher in gross plots than in net plots. After correction for stand the highest values of $\rho_{\mathrm{p}}$ were obtained. 


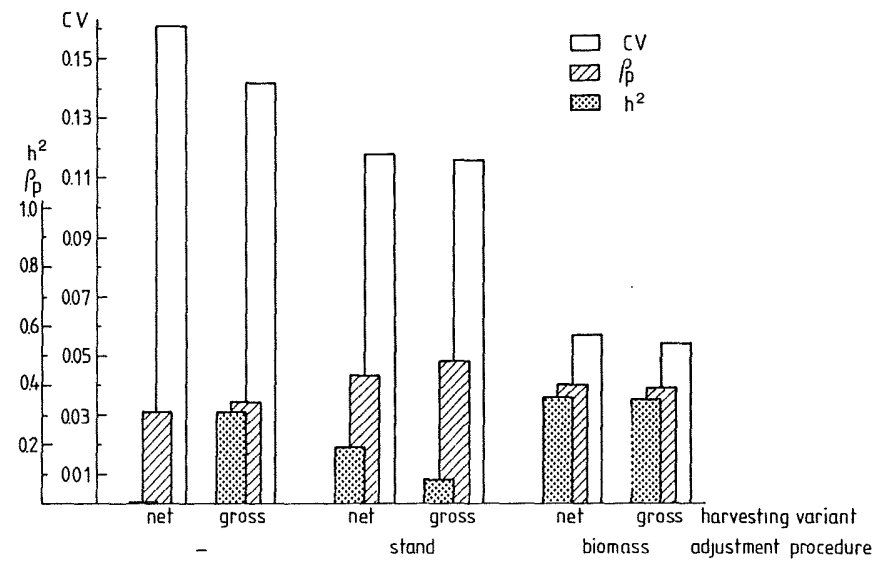

Fig. 1. Heritability $\left(\mathrm{h}^{2}\right)$, phenotypic correlation coefficient $\left(\rho_{\mathrm{p}}\right)$ with 'farm' yield and variation coefficient (CV) of grain yield in single-row selection plots with single row-spacing $(\simeq 20 \mathrm{~cm})$.

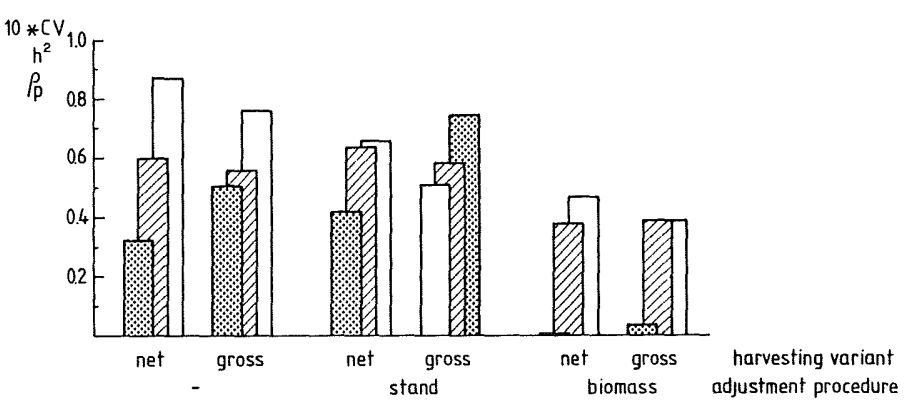

Fig. 2. Heritability $\left(h^{2}\right)$, phenotypic correlation coefficient $\left(\rho_{\mathrm{p}}\right)$ with 'farm' yield and variation coefficient (CV) of grain yield in single-row selection plots with double row-spacing $(\simeq 40 \mathrm{~cm})$

Double row-spacing $(\simeq 40 \mathrm{~cm})$. Averaged over all the harvesting variants $\mathrm{CV}$ was almost halved in comparison with the single-row variants with single row-spacing (Fig. 2). Furthermore, CV was like the previous case lower in gross plots than in net plots. The effects of correction on $\mathrm{CV}$ ran parallel with single row-spaced single-row plots. The heritability was improved to a somewhat lesser extent than CV by going to a double row-spacing. In gross plots $\mathrm{h}^{2}$ was higher than in net plots.

The variety effect for grain yield was only significant after stand correction, irrespective of the fact whether gross or net plots were harvested. In contrast correction for biomass led to an almost complete elimination of variety differences. The quantity $\rho_{\mathrm{p}}$ was approximately the same in net and gross plots. After biomass correction $\rho_{\mathrm{p}}$ was considerable lower than after other harvesting variants. On the average $\rho_{\mathrm{p}}$ was $35 \%$ higher than in the single row-spaced single-row plots.

\section{Three-row plots}

The net plots had a CV which was equal to or larger than that of gross plots (Fig. 3 and 4). Both correction methods decreased $\mathrm{CV}$, mostly by the biomass correction. 


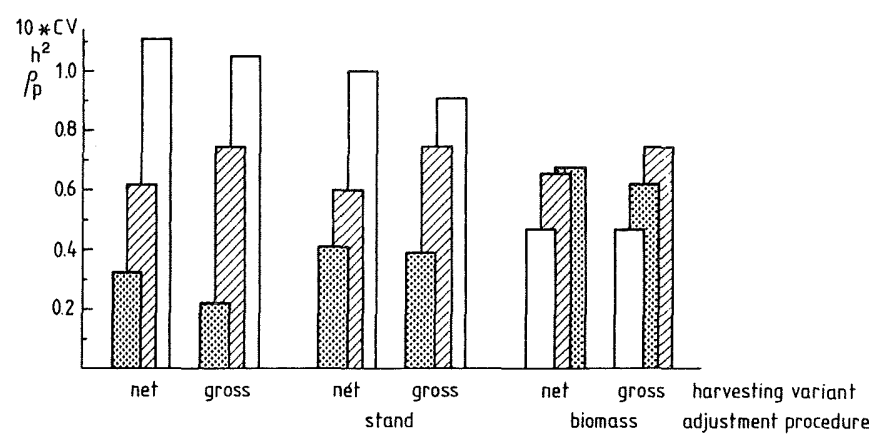

Fig. 3. Heritability $\left(\mathrm{h}^{2}\right)$, phenotypic correlation coefficient $\left(\rho_{\mathrm{p}}\right)$ with 'farm' yield and variation coefficient (CV) of grain yield in central three-row selection plots.

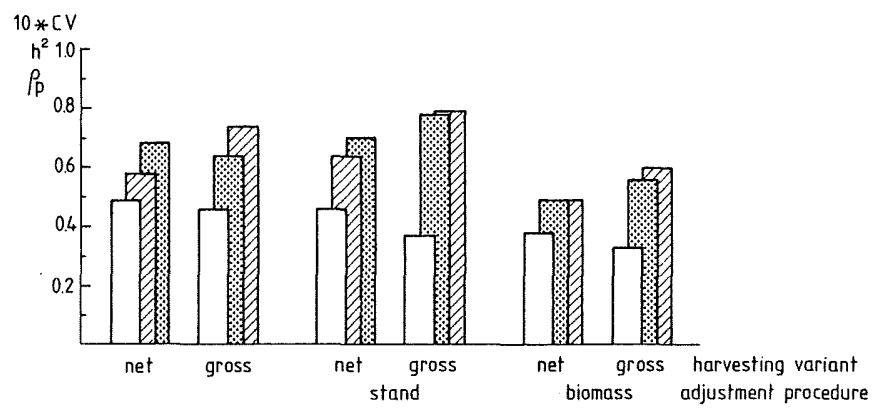

Fig. 4. Heritability $\left(\mathrm{h}^{2}\right)$, phenotypic correlation coefficient $\left(\rho_{\mathrm{p}}\right)$ with 'farm' yield and variation coefficient (CV) of grain yield in total three-row selection plots.

For central plots (single rows) CV was approximately twice as large as for the total plots, except after biomass correction, when the difference was smaller. For central plots $\mathrm{CV}$ was considerably smaller than for unbordered single-row plots, with single row-spacing. The quantity of sampled plant material was in both cases the same.

Net and gross plots had about the same $\mathrm{h}^{2}$. Correction of plot yield for stand or biomass increased $\mathrm{h}^{2}$, except in the case of biomass correction of total plot yields. Further $\mathrm{h}^{2}$ of total plot yield was higher than of central plots, except after biomass correction. The estimate for $\rho_{\mathrm{p}}$ from net plots was approximately $80 \%$ of that for gross plots.

Neither correction method improved $\rho_{\mathrm{p}}$. Rather the opposite was the case, especially after biomass correction. The quantity $\rho_{\mathrm{p}}$ for central plots was the same as for total plots. Both $\mathrm{h}^{2}$ and $\rho_{\mathrm{p}}$ of central plots were higher than for unbordered single-row plots with single row-spacing.

\section{Six-row plots}

The CV of gross plots was approximately $20 \%$ lower than that of net plots, and about the same level as for total three-row plots (Fig. 4, 5, 6). The effect of both correction methods on $\mathrm{CV}$ was negligible. Harvesting central plots instead of total plots also hardly resulted in a decrease of $\mathrm{CV}$. The quantity $\mathrm{h}^{2}$ was higher in gross plots than in net plots. It was slightly improved by harvesting total plots instead of central plots. 


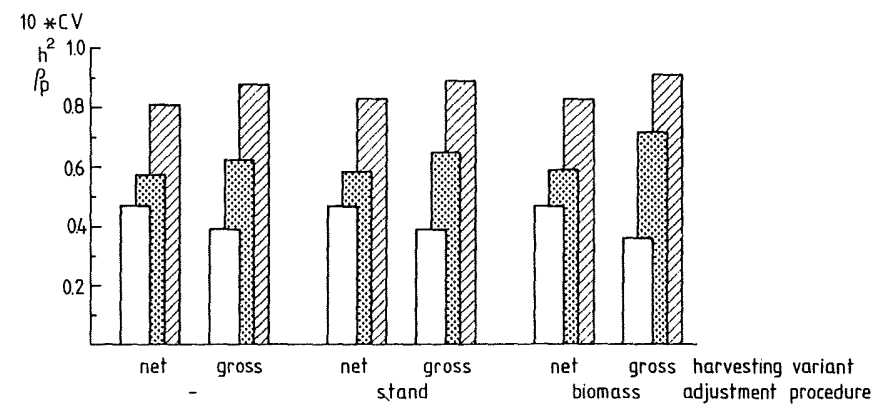

Fig. 5. Heritability $\left(\mathrm{h}^{2}\right)$, phenotypic correlation coefficient $\left(\rho_{\mathrm{p}}\right)$ with 'farm' yield and variation coefficient (CV) of grain yield in central six-row selection plots.

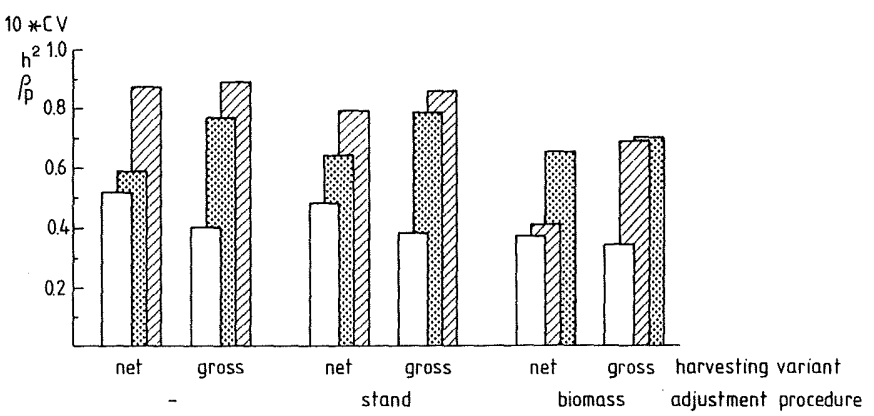

Fig. 6. Heritability $\left(\mathrm{h}^{2}\right)$, phenotypic correlation coefficient $\left(\rho_{\mathrm{p}}\right)$ with 'farm' yield and variation coefficient (CV) of grain yield in total six-row selection plots.

Correction had a negligible influence. The quantity $\mathrm{h}^{2}$ was only slightly lower than the estimate of $h^{2}$ in the yield trial.

The quantity $\rho_{\mathrm{p}}$ for central and that for total plots were about the same except for total plots after biomass correction (in which case $\rho_{\mathrm{p}}$ was considerably lower). In all other variants $\rho_{\mathrm{p}}$ was close to one, indicating that selection on mean yield in such plots was almost as effective as in the yield trial. The estimates for $\rho_{\mathrm{p}}$ in the six-row plots were only slightly higher than those in the three-row plots.

\section{DISCUSSION}

General. The performance of varieties in the yield trial is thought to be the best criterion for variety rating and supposedly representative for performance under farm conditions.

A high $\mathrm{h}^{2}$ and a low $\mathrm{CV}$ in the selection plots need not necessarily indicate that selection will be effective, since the situation in the selection nursery may not be representative for the farm situation. For instance, a variety with a consistently high yield in the selection nursery may realize this potential by strong competition and infringement of alley space. Under farm conditions such a variety may disappoint. The single criterion for judgement of the effectiveness of selection plot variants in the nursery is $\rho_{\mathrm{p}}$, the phenotypic correlation coefficient between plot yield and monoculture yield or farm yield. The quantity $\rho_{\mathrm{p}}$ is a function of $\mathrm{h}^{2}$ both in selection plots and the yield 
experiment, and of $\rho_{\mathrm{g}}$, the coefficient of genetic correlation between grain yield in the selection situation and in the yield trial (see appendix). The disadvantage of the use of $\rho_{\mathrm{p}}$ is that it hides the underlying causes of the selection response. Its convenience is that plot types can be compared by means of a single parameter.

Gross versus net plots. Frequently net plots are harvested with the purpose to remove alley effects and to obtain in this way an unbiased estimate of monoculture performance. The disadvantage of such a procedure is that the sampled area is decreased so that random effects become more important. These increased disturbing random effects in net plots may become more important than the bias due to alley effects in gross plots.

In all selection plots harvesting of gross plots appeared to decrease the coefficient of variation, indicating the benefit of a greater sample size. Also in the six-row plots $\mathrm{CV}$ for gross plots was clearly and significantly lower than for net plots.

Infringement on alley space can be interpreted as a response to wider spacing. Like with the effect of spacing, little effect of alleys on the genetic CV $(=\sqrt{\operatorname{var} g / \bar{x}})$ is expected (SPITTERS, 1979: p. 227, 231). As the (environmental) CV for gross plots was lower than for net plots, the heritability in gross plots increased compared with net plots. Only in single-row plots $(\simeq 20 \mathrm{~cm})$ and in the central rows of three-row plots this was not the case. However, to these exceptions no serious attention need be paid, since in these cases no significant variety differences for grain yield could be demonstrated.

In nearly all variants the phenotypic correlation coefficient between selection plot performance and grain yield in the yield trial was higher in the gross plots than in the corresponding net variants. Apparently, the advantage of a greater sampled area (higher $h^{2}$ ) outweighed the disadvantage of a variable reaction of the varieties to the alleys (which decreases $\rho_{\mathrm{g}}$ ).

The best selection results are thus expected when gross plots are harvested. In practice this would also be preferred. In all the present selection plots slightly more than $30 \%$ of the yield of gross plots was neglected by harvesting only net plots. Based on the soil area occupied by gross and net plots one would expect a difference of $25 \%$ in yield. The deviation from the expected $25 \%$ yield difference is the alley effect on grain yield. Since the potential area to be sampled is too much reduced by harvesting net plots instead of gross plots and since the degree in which varieties differ with respect to alley effects is so small, removing borders before harvesting selection plots should not be recommended. In very small plots the loss in area to be sampled would be prohibitive, in large plots the border effects become insignificant. Moreover, the seed multiplication potential would not be fully exploited by harvesting net plots.

Single versus double row-spacing of single-row plots. Competition between genotypes growing in neighbouring plots can be avoided by chosing a wide row-spacing. At the same time this introduces a bias due to differential reactions of genotypes to additional space (SPITTERS, 1979: p. 77). In our experiments with single-row plots, doubling the row-spacing was clearly advantageous. The coefficient of variation decreased, and $\mathrm{h}^{2}$ and $\rho_{\mathrm{p}}$ increased except after biomas adjustement. The lower CV is in contrast with results of SPITTERS (1979; Table 55) who found no effect of wide row-spacing on $\mathrm{CV}$. In the present experiment the relation between the standard deviation and 
Table 3. Effect of plot-type on mean, genetic variance, environmental variance heritability and coefficient of variation for grain yield plot $^{-1}$. For convenience, the mean is expressed in $\mathrm{g} \mathrm{m}^{-2}$ and the variance in $\mathrm{g}^{2} \mathrm{~m}^{-4}$. Results refer to gross plots.

\begin{tabular}{lcrrrl}
\hline Plot-type & Mean & var $\mathrm{g}$ & var $\underline{\mathrm{e}}$ & $\mathrm{h}^{2 \prime}$ & $\mathrm{CV}^{\prime}$ \\
& & & & & \\
single-row plots $(\simeq 20 \mathrm{~cm})$ & 359 & 1154 & 10445 & 0.10 & 0.28 \\
single-row plots $(\simeq 40 \mathrm{~cm})$ & 301 & 557 & .2115 & 0.21 & 0.15 \\
$\begin{array}{l}\text { three-row plots } \\
\quad \text { 3-rows }\end{array}$ & 362 & 506 & 1115 & 0.31 & 0.09 \\
$\quad$ central row & 391 & 498 & 6713 & 0.07 & 0.21 \\
six-row plots & & & & & \\
$\quad$ 6-rows & 352 & 674 & 797 & 0.46 & 0.08 \\
$\quad$ central rows & 351 & 344 & 727 & 0.32 & 0.08 \\
yield trial & 324 & 645 & 360 & 0.64 & 0.06 \\
\hline
\end{tabular}

Table 4. Coefficient of genetic correlation $\left(\rho_{\mathrm{g}}\right)$ of grain yield in several selection plot-types with grain yield in the yield trial.

\begin{tabular}{ll}
\hline Plot-type & $\rho_{\mathrm{g}}$ \\
single-row plots $(\simeq 20 \mathrm{~cm})$ & 0.64 \\
single-row plots $(\simeq 40 \mathrm{~cm})$ & 0.83 \\
three-row plots & \\
3-rows & 0.98 \\
central row & 1.66 \\
six-row plots & 1.08 \\
6-rows & 1.18 \\
$\quad$ central 4 rows & \\
\hline
\end{tabular}

the mean is apparently rather hyperbolic than linear. Possible explanations for the decrease in CV with wider spacings are given by SPITTERs (1979: p. 90). The reason for the superior selection response expected in wide spaced row-plots is the relatively larger decrease of the environmental variance var e in relation to the decrease of the genetic variance var $\mathrm{g}$ (Table 3). The genetic correlation $\rho_{\mathrm{g}}$ with the yield trial performance is rather similar for both plot-types (Table 4). Under certain conditions, the rank of the genotypes in a mixture is independent of the spacing at which the mixture is grown (SPITTERS, 1979: p. 88). These conditions appear to be met in this experiment.

Central plots versus total plots. Competition between neighbouring plots can also be avoided by harvesting only central plots and elimination of the border rows. Then, a possible competitional bias is replaced by an increase in random effects, due to a smaller sampled area. Also, a larger within block error variance is to be expected with an increase in land requirement.

When unbordered single-row plots $(\simeq 20 \mathrm{~cm})$ are compared with bordered singlerow plots (the central rows of three-row plots) the following effects are observed. In bordered plots the coefficient of variation is considerably smaller as a result of the lower var e (Table 3). The heritability is also lower, due to the fact that the relative decrease of var $\underline{g}$ is larger than the relative decrease of var $\underline{\mathrm{e}}$ (Table 3). Yet, $\rho_{\mathrm{p}}$ is 
higher, because the increase of the genetic correlation coefficient $\rho_{\mathrm{g}}$ with farm yield outweighed the lower heritability (Table 4). Comparing the central row of three-row plots with the total plots, the coefficient of variation of total plots is much smaller and the heritability higher. However, $\rho_{\mathrm{p}}$ for both plots is similar. Apparently, the lower heritability of central plots is compensated for by the higher $\rho_{\mathrm{g}}$ with farm yield in the yield trial. This is in contrast with results obtained by SPITTERS (1979: p. 242) who found that the gain in $\mathrm{h}^{2}$ by harvesting total three-row plots was not annulled by a loss in $\rho_{\mathrm{g}}$ with monoculture yield.

The results obtained with the six-row total and central variants correspond with the three-row plot variants. However, the differences between estimates of $h^{2}, \mathrm{CV}$ and $\rho_{\mathrm{p}}$ in the six-row variants are more gradual than in three-row plot variants. Therefore, as far as the selection response for farm yield is concerned it makes no difference whether one harvests central or total six-row plots. In practise one probably will prefer to harvest total plots because of machine harvesting procedures. The higher quantity of harvested seed will again be an additional factor. Total gross plots thus promise the best selection results.

Effect of adjustment. Correction for stand caused especially in the smaller plots a decrease of the $\mathrm{CV}$ and an improvement of $\mathrm{h}^{2}$. The reason is that adjustment eliminates part of the error variance. The effect of adjustment on the phenotypic correlation coefficient with farm yield was negligable, except for single-row plots with single rowspacing.

Thus, no important improvement of the selection efficiency was expected with this type of adjustment. The improvement to be made by harvesting gross plots instead of net plots is much more important.

Yield adjustment on the basis of biomass supposedly corrects not only for differences in stand but also for differences among the genotypes in competitive ability. Differences in competitive ability of genotypes cause strong competitors to yield relatively high in mixture, whereas in monoculture such an advantage disappears. However, it should be realized that differences in biomass of genetic origin were present among the entries included in this experiment, since significant differences for this character were observed in the yield trial. As a matter of fact, grain yield differences in the yield trial were more closely associated with variation in biomass $\left(\rho_{\mathrm{p}}=0.72\right)$ than with variation in harvest-index $\left(\rho_{\mathrm{p}}=0.15\right.$, Table 2$)$. The major contribution to biomass differences came from the varieties Mexipak and Pitic. These varieties had a considerable shorter growth duration.

The adjustment method based on biomass differences will thus eliminate the latter real differences between the genotypes. The usefulness of this correction method therefore depends on the relative contribution of stand and competitional differences to biomass differences on the one hand and genetical causes of biomass differences on the other hand. Since biomass adjustment in the selection experiments in general lowered the phenotypic correlation coefficient with grain yield in monoculture, it must be concluded that stand and competitional causes of biomass differences were here of minor importance to the genetic causes of these differences. 
TH. KRAMER, J. W. VAN OOIJEN AND C. J. T. SPITTERS

Table 5. Grain yield in $\mathrm{g} \mathrm{m}^{-2}$ of single-row plots $(\simeq 20 \mathrm{~cm}$ and $\simeq 40 \mathrm{~cm}$ row distance), three-row plots, six-row plots and yield trial. The yields of the selection plots are based on gross plot yields.

\begin{tabular}{|c|c|c|c|c|c|c|c|}
\hline \multirow[t]{2}{*}{ Variety } & \multicolumn{2}{|c|}{ Single-row plots } & \multicolumn{2}{|c|}{ Three-row plots } & \multicolumn{2}{|c|}{ Six-row plots } & \multirow{2}{*}{$\begin{array}{l}\text { Yield } \\
\text { trial }\end{array}$} \\
\hline & $\begin{array}{l}\text { narrow } \\
(\simeq 20 \mathrm{~cm})\end{array}$ & $\begin{array}{l}\text { wide } \\
(\simeq 40 \mathrm{~cm})\end{array}$ & total & central & total & central & \\
\hline Arabel & 322 & 322 & 406 & 396 & 362 & 353 & 315 \\
\hline Bastion & 240 & 259 & 341 & 353 & 341 & 343 & 308 \\
\hline Ceb. 1052 & 362 & 329 & 389 & 398 & 396 & 396 & 364 \\
\hline Ceb. 7651 & 386 & 296 & 386 & 482 & 382 & 362 & 352 \\
\hline vdH. $1040-73$ & 379 & 295 & 396 & 418 & 370 & 367 & 340 \\
\hline $\mathrm{vdH} .1102-73$ & 396 & 323 & 386 & 442 & 355 & 365 & 338 \\
\hline H $859-3$ & 257 & 269 & 331 & 367 & 365 & 374 & 340 \\
\hline Kaspar & 374 & 289 & 370 & 353 & 350 & 350 & 340 \\
\hline Kleiber & 444 & 293 & 360 & 389 & 343 & 336 & 328 \\
\hline LD 374171 & 307 & 296 & 355 & 394 & 343 & 370 & 319 \\
\hline Mexipak & 322 & 239 & 300 & 326 & 283 & 307 & 261 \\
\hline MG 18-74 & 442 & 366 & 377 & 461 & 374 & 360 & 350 \\
\hline Pitic & 382 & 304 & 326 & 312 & 307 & 314 & 280 \\
\hline Selpek & 394 & 311 & 334 & 386 & 334 & 336 & 314 \\
\hline Toro & 427 & 349 & 374 & 422 & 398 & 367 & 332 \\
\hline Triesdorf & 298 & 270 & 346 & 341 & 341 & 329 & 300 \\
\hline mean & 358 & 301 & 362 & 391 & 352 & 351 & 324 \\
\hline$\sigma_{\overline{\mathrm{x}}}(\mathrm{n}=4)$ & 51.1 & 23.0 & 16.7 & 41.0 & 14.1 & 13.5 & 9.5 \\
\hline
\end{tabular}

Finally, it should be pointed out that adjustment of grain yield by means of biomass is comparable to selection for harvest-index (SPITTERs, 1979: p. 187-191). The adjustment used here, with biomass as a covariable, has the advantage that overadjustment is avoided.

Analysis of yield per $\mathrm{m}^{2}$. To illustrate the principles of the results obtained with the various plot-types in more detail an analysis was performed for only gross yield per plot. To facilitate the comparison between the different selection plots, their yields were expressed in $\mathrm{g} \mathrm{m}^{-2}$ and their variances in $\mathrm{g}^{2} \mathrm{~m}^{-4}$ (Table 3 ). The mean grain yields of the 16 varieties are presented in Table 5 .

The genetic variance of single-row unbordered plots $(\simeq 20 \mathrm{~cm})$ is more than twice as high as var $\mathrm{g}$ of bordered single-row plots (= central rows of three-row plots). This difference in genetic variance must be due to intergenotypic competition, which magnified the difference between the varieties. The environmental variance of the central rows was much smaller than var $\mathrm{e}$ of unbordered single-row plots $(\simeq 20 \mathrm{~cm})$. A smaller var e for bordered single-row plots is expected, since bordered plots have a uniform genetic environment. However, this difference is more extreme than expected (SPITTERS, 1979: p. 57, 242). Probably estimation errors have also contributed to this difference. The combined effects of changes in var $\mathrm{g}$ and vare result in a somewhat lower heritability for bordered plots. The selection response to be expected is however higher in bordered single-row plots, since the genetic correlation coefficient $\rho_{\mathrm{g}}$ is higher and outweighs the slightly lower $h^{2}$ (Table 4 ). This result is in contrast with that of 
Spitters, who found that selection in unbordered single-row plots was slightly more efficient (SprTrERs, 1979: p. 242).

Widening the row-spacing of single-row plots to $\simeq 40 \mathrm{~cm}$ appeared advantageous. The genetic variance was decreased; the environmental variance even more so. As a consequence, the heritability was approximately twice as high as in unbordered narrow-spaced $(\simeq 20 \mathrm{~cm})$ single-row plots. The decrease of var g may be ascribed to smaller differences among the varieties in their reaction to available space than the differences in their competitive ability. The genetic variance in wide-spaced single-row plots was of the same order of magnitude as in bordered single-row plots at normal spacing $(\simeq 20 \mathrm{~cm})$. The environmental variance is however lower than would be expected on the basis of the difference in sample weight, which is for wide-spaced single-row plots 1.7 times larger than for normal spaced single-row plots (Table 1). Therefore, the environmental variance expected for wide-spread single-row plots var $\mathrm{e}_{40}$ is at least var $\mathrm{e}_{20} / 1.7=6144 \mathrm{~g}^{2} \mathrm{~m}^{-4}$. When wide-spaced single-row plots are considered as plots bordered by empty rows the expected error variance would be equal to the error variance of central rows of three-row plots, divided by $1.5(250 / 163$, Table 1$)$ is $4475 \mathrm{~g}^{2} \mathrm{~m}_{-4}$. Both expectations are higher than the observed var e for wide-spread single-row plots. The reasons for this discrepancy may be the heterogeneity of the trial area or random variation of var e.

The unexpected low error variance in wide-spaced single-row plots increases the heritability. Consequently, $\rho_{\mathrm{p}}$ and thus the expected response after selection may be too optimistic.

In multiple-row selection plots the genetic variance of total plots was larger than of central plots. A large genetic variance of total plots is expected, since intergenotypic competition increased var $\mathrm{g}$ in this experiment. However, the difference in var $\mathrm{g}$ between total and central six-row plots is much larger than expected. A possible explanation is the random variation in the estimate of the genetic variance. The environmental variance of multiple-row plots $\mathrm{m}^{-2}$ becomes in general lower with an increase in plot size. The reason is that larger plots sample more of the heterogeneity of the soil. The within-plot variance (not detected) then becomes larger, and the between plot variance smaller. The combined effects of var $\mathrm{g}$ and var e caused total plots to have higher heritability values than central plots. In addition, $\mathrm{h}^{2}$ increased with the plot size.

The heritability values and the genetic correlation coefficients with grain yield in the yield trial predict the selection efficiencies to be realized in the different plot-types. Selection in the six-row plots of $2.5 \mathrm{~m}^{2}$ was just as efficient as in the $9 \mathrm{~m}^{2}$ plots of the yield trial. In such a situation the phenotypic correlation $\rho_{\mathrm{p}}$ between grain yield in the selection experiment and in the yield trial is equal to $h_{y}^{2}$, the heritability in the yield trial (see appendix). A similar conclusion was reached by BAKER \& KOSMOLAK (1977) for variety trials at 2 locations.

Selection response. A variety with a high yield under farming conditions is the ultimate objective of breeding efforts. Farming conditions were simulated in the yield trial sown with the Øyord sowing machine. Standard cultural practices of fertilization and crop protection were applied. However, selection took place in small plots, whether or not influenced by intergenotypic competition, sown with a seedmatic machine at a different row-spacing. Therefore, grain yield in the yield trial should be considered as the 
TH. KRAMER, J. W. VAN OOIJEN AND C. J. T. SPITTERS

Table 6. Expected and realized response for 'farm' yield as measured in the yield trial in $\mathrm{g} \mathrm{m}^{-2}$ after selection for grain yield in different selection plots. The selection intensity $\mathrm{i}=1.25$.

\begin{tabular}{lll}
\hline & \multicolumn{2}{l}{ Selection response } \\
\cline { 2 - 3 } Plot-type & expected & observed \\
& 6 & 6 \\
single-row plots $(\simeq 20 \mathrm{~cm})$ & 12 & 9 \\
single-row plots $(\simeq 40 \mathrm{~cm})$ & 17 & 16 \\
three-row plots & 14 & 13 \\
$\quad 3$ rows & & \\
$\quad$ central row & 23 & 17 \\
six-row plots & 21 & 16 \\
$\quad$ 6-rows & & \\
$\quad$ central 4 rows & &
\end{tabular}

target trait, with grain yield in the selection plots as an auxilliary trait for indirect selection. In analogy with the formula derived by SPITTERS (1979: p. 61) for a correlated response for monoculture yield when selecting in mixture, the response for grain yield in the yield trial can be predicted from (a) the selection intensity $i_{x}$, (b) the square root of the heritability $h_{x}^{\prime}$ in the selection plots, (c) the genetic correlation between grain yield in the selection plots and in the yield trial and (d) the genetic standard

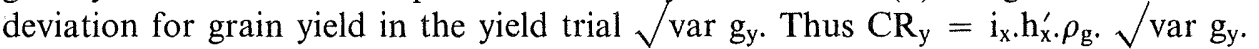
The same formula was derived by Falconer for indirect selection (FALCONER, 1960: p. 318). The genetic correlation coefficients $\rho_{\mathrm{g}}$ between grain yield in the various selection plots and in the yield trial were estimated on the basis of the heritabilities and the phenotypic correlation coefficient $\rho_{\mathrm{p}}$ of the variety means in both experiments (see appendix). The coefficients of genetic correlation are presented in Table 4. Some coefficients were higher than 1 . This is not unusual (Bos, 1981; p. 124) and must be ascribed to inaccuracy of the estimators.

The response for grain yield in the yield trial $\mathrm{CR}_{\mathrm{y}}$ predicted on the basis of genetic parameters was compared with actual selection in the selection plots and expressed in $\mathrm{g} \mathrm{m}^{-2}$. It was decided to select $25 \%$ (16 out of 64$)$ best yielding entries in each selection experiment. Under the assumption of normality for grain yield, the selection intensity $i_{x}$ is then 1.25 (BECKER, 1975). The actual response is the difference between the weighted mean yield in the yield trial of the selected varieties and the mean yield of all varieties in this experiment. The results are presented in Table 6 . The expected responses were somewhat lower than the actual response.

\section{APPENDIX}

1. Anova table of a randomized block design with 16 varieties in 4 replications

\begin{tabular}{lrl}
\hline Source of variation & df & EMS \\
correction term & 1 & \\
replications & 3 & var $\underline{\mathrm{e}}+16 \operatorname{var} \underline{\mathrm{b}}$ \\
varieties & 15 & var $\underline{\mathrm{e}}+4 \operatorname{var} \underline{\mathrm{g}}$ \\
error & 45 & var $\underline{\mathrm{e}}$ \\
total & 64 & \\
\hline
\end{tabular}


2. Estimation procedures of $\mathrm{CV}, \mathrm{h}^{2}, \rho_{\mathrm{g}}$ and $\rho_{\mathrm{p}}$. The subscripts $\mathrm{x}$ and y refer to grain yield in the selection experiment and the yield trial respectively.

$\mathrm{CV}^{\prime}=\sqrt{\text { var } \mathrm{e} / \mathrm{m}}$ where $\mathrm{m}$ is the mean yield over 4 replications

$\mathrm{h}^{2 \prime}=\frac{\operatorname{var} \mathrm{g}}{\operatorname{varg}+\operatorname{var} \underline{\mathrm{e}}}$

The quantities $\mathrm{CV}$ and $\mathrm{h}^{2}$ refer to means over 4 replications $\left(\frac{1}{4}\right.$ var e is substituted instead of var e), $\mathrm{CV}^{\prime}$ and $\mathrm{h}^{2 \prime}$ to individual observations. In analogy $\rho_{\mathrm{g}}{ }^{\prime}$ and $\rho_{\mathrm{p}}{ }^{\prime}$ are also estimates for individual observations.

When $p_{x i}$ and $p_{y i}$ are phenotypic values of genotype $i(i=1,16)$ in the selection experiment and in the yield trial then

$\mathrm{p}_{x i}=\mu_{x}+g_{x i}+\underline{e}_{x i}$ and $p_{y i}=\mu_{y}+g_{y i}+\underline{e}_{y i}$

The phenotypic correlation coefficient $p_{\mathrm{p}}{ }^{\prime}$ between $\mathrm{p}_{\mathrm{xi}}$ and $\mathrm{p}_{\mathrm{yi}}$ is

$\rho_{\mathrm{p}}{ }^{\prime}=\frac{\operatorname{cov}\left(\mathrm{p}_{\mathrm{x} i}, \mathrm{p}_{\mathrm{y} i}\right)}{\sqrt{\operatorname{var} \underline{p}_{\mathrm{x}} \cdot \operatorname{var} \underline{p}_{\mathrm{y}}}}=\frac{\operatorname{cov}\left(\mu_{\mathrm{x}}+\mathrm{g}_{\mathrm{xi}}+\underline{\mathrm{e}}_{\mathrm{x} i}, \mu_{\mathrm{y}}+\mathrm{g}_{\mathrm{yi}}+\underline{\mathrm{e}}_{\mathrm{yi}}\right)}{\sqrt{\operatorname{var} \underline{p}_{\mathrm{x}} \cdot \operatorname{var} \underline{p}_{\mathrm{y}}}}$

Since $g_{x i}$ and $\underline{e}_{x i}, g_{y i}$ and $\underline{e}_{y i}$, and $\underline{e}_{x i}$ and $\underline{e}_{y i}$ are supposed to be independant

$\rho_{\mathrm{p}}{ }^{\prime}=\frac{\operatorname{cov}\left(\mathrm{g}_{\mathrm{x}}, \mathrm{g}_{\mathrm{yi}}\right)}{\sqrt{\operatorname{var} \underline{p}_{\mathrm{x}} \cdot \operatorname{var} \underline{p}_{\mathrm{y}}}}$

In analogy $\rho_{\mathrm{g}}^{\prime}=\frac{\operatorname{cov}\left(\mathrm{g}_{\mathrm{x}}, \mathrm{g}_{\mathrm{yi}}\right)}{\sqrt{\operatorname{var} \mathrm{g}_{\mathrm{x}} \cdot \operatorname{var} \underline{g}_{\mathrm{y}}}}$

Entering (1) in (2) gives

$\rho_{\mathrm{g}}{ }^{\prime}=\rho_{\mathrm{p}}{ }^{\prime} \cdot \frac{\sqrt{ } \operatorname{var} \mathrm{p}_{\mathrm{x}} \cdot \operatorname{var} \mathrm{p}_{\mathrm{y}}}{\sqrt{\operatorname{var} \mathrm{g}_{\mathrm{x}} \cdot \operatorname{var} \mathrm{g}_{\mathrm{y}}}}=\rho_{\mathrm{p}}{ }^{\prime} \frac{1}{\mathrm{~h}_{\mathrm{x}}{ }^{\prime} \cdot \mathrm{h}_{\mathrm{y}}{ }^{\prime}}$

In analogy, when $\overline{\mathrm{p}}_{\mathrm{xi}}$ and $\overline{\mathrm{p}}_{\mathrm{yi}}$ are mean phenotypic values over 4 replications in the selection experiment and in the yield trial

$\rho_{\mathrm{p}}=\frac{\operatorname{cov}\left(\overline{\mathrm{g}}_{\mathrm{x} i}, \overline{\mathrm{g}}_{\mathrm{yi}}\right)}{\sqrt{\operatorname{var} \overline{\mathrm{p}}_{\mathrm{x}} \cdot \operatorname{var} \overline{\mathrm{p}}_{\mathrm{y}}}}$ and $\rho_{\mathrm{g}}=\rho_{\mathrm{p}} \frac{1}{\mathrm{~h}_{\mathrm{x}} \cdot \mathrm{h}_{\mathrm{y}}}$

3. The relative selection efficiency RSE is the ratio of the correlated response for 'farm' yield $C R_{y}$ when selection is applied in a selection plot to the direct response $R_{y}$ by selecting for 'farm' yield in the yield trial.

Thus RSE $=\frac{\mathrm{CR}_{\mathrm{y}}}{\mathrm{R}_{\mathrm{y}}}=\frac{\mathrm{i}_{\mathrm{x}} \cdot \rho_{\mathrm{g}} \cdot \mathrm{h}_{\mathrm{x}} \cdot \sqrt{ } \operatorname{varg}_{\mathrm{y}}}{\mathrm{i}_{\mathrm{y}} \cdot \mathrm{h}_{\mathrm{y}} \cdot \sqrt{\operatorname{var} \mathrm{g}_{\mathrm{y}}}}(4)$

where $\rho_{\mathrm{g}}$ is the coefficient of genetic correlation between yield in the selection plot and 'farm' yield (SPITTERS, 1979: p. 61). The subscripts $x$ and $y$ refer to selection plots 
and yield trial. When $i_{x}=i_{y}$ and by substitution of (3) into (4) it follows that

$\mathrm{RSE}=\rho_{\mathrm{p}} \cdot \frac{1}{\mathrm{~h}^{2} \mathrm{y}}$

\section{REFERENCES}

Alessandroni, A. \& M. C. SCAlfati, 1973. Early-generation selection for grain yield of dwarf and semidwarf progenies of durum wheat crosses. Proc. 4th Intern. Wheat Genetics Symp. Columbia, Miss. pp. 475-482.

Aguilar, M. I. \& R. A. Fischer, 1975. Analysis de crecimiento y rendimiento de genotipos de trigo bajo condiciones ambientales optimas de cultivo. Agrociencia (Mexico) 21: 185-198.

Austin, R. B. \& R. D. BlaCKWELL, 1980. Edge and neighbour effects in cereal yield trials. J. agric. Sci., Camb. 94: 731-734.

BAKER, R. J. \& F. G. KOSMOLAK, 1977. Effects of genotype - environment interaction on bread wheat quality in western Canada. Can. J. Plant Sci. 57: 185-191.

BeCKER, W. A., 1975. Manual of quantitative genetics. Washington State Univ. Press. Pullman, Washington.

Bos, I., 1981. The relative efficiency of honeycomb selection and other procedures for mass selection in winterrye (Secale cereale L.) 172 p. Doctoral thesis, Agricultural University, Dept. Plant Breeding, Wageningen.

BRIGGS, K. G. \& L. H. SHEBESKI, 1971. Early generation selection for yield and breadmaking quality of hard red spring wheat (Triticum aestivum L. em THELL). Euphytica 20: 453-463.

DePAuw, R. M. \& L. H. ShebeSKI, 1973. An evaluation of early generation yield testing procedure in Triticum aestivum. Can. J. Plant Sci. 53: 465-470.

Donald, C. M. \& J. Hamblin, 1976. The biological yield and harvest-index of cereals as agronomic and plant breeding criteria. Adv. Agron. 28: 361-405.

FALCONER, D. S., 1960. Introduction to quantitative genetics. Ronald Press Company, New York.

FISCHER, R. A., 1979. Are your results confounded by intergenotypic competition? Proc. 5th Int. Wheat Genet. Symp., Febr. 23-28, 1978. New Dehli, India, p. 769-776.

JAIN, H. K. \& V. P. KULSHRESTHA, 1976. Dwarfing genes and breeding for yield in bread wheat. Z. Pflanzenzüchtg 76: 102-112.

Kramer, Th., 1979. Enivoronmental and genetic variation for protein content in winter wheat (Triticum aestivum L.). Euphytica 28: 209-218.

Sertzer, J. F. \& L. E. Evans, 1978. Yield gains in wheat by the pedigree method of selection and two early yield tests. Z. Pflanzenzüchtg 80: 1-10.

SHEBESKI, L. H., 1967. Wheat and wheatbreeding. Proc. Can. Centennial Wheat Symp. (Ed. K. F. Nielson). Modern Press, Saskatoon. p. 249-272.

SPITTERS, C. J. T., 1979. Competition and its consequences to selection in barley breeding. Agric. Res. Rep. 893, Wageningen, 268 p.

SYmE, J. R., 1970. A high-yielding Mexican semi-dwarf wheat and the relationship of yield to harvest-index and other varietal characteristics. Austr. J. Exp. Agric. Anim. Husb. 10: 350-353.

VEN, A. C. M., VAN DE, 1981. De invloed van standafwijkingen op de opbrengst bij zomertarwe. Internal Research Report, Library Dept. Plantbreeding, pp. 73.

Whan, B. R., A. J. RATHJEN \& R. KNiGht, 1981. The relation between wheat lines derived from the $F_{2}$, $F_{3}, F_{4}$ and $F_{5}$ generations for grain yield and harvest index. Euphytica 30: 419-429.

Whan, B. R., R. KNIGHT \& A. J. RATHJen, 1982. Response to selection for grain yield and harvest index in the $F_{2}, F_{3}$ and $F_{4}$ of two wheat crosses. Euphytica 31 , accepted. 